\title{
Thermal Characteristics of InGaN/GaN Flip-Chip Light Emitting Diodes with Diamond-Like Carbon Heat-Spreading Layers
}

\author{
Pai-Yang Tsai, ${ }^{1}$ Hou-Kuei Huang, ${ }^{1}$ Chien-Min Sung, ${ }^{2}$ \\ Ming-Chi Kan, ${ }^{2}$ and Yeong-Her Wang ${ }^{1}$ \\ ${ }^{1}$ Institute of Microelectronics, Department of Electrical Engineering, Advanced Optoelectronic Technology Center, \\ National Cheng Kung University, Tainan 701, Taiwan \\ ${ }^{2}$ Department of DLC Technology, RiteDia, Hsin Chu 303, Taiwan
}

Correspondence should be addressed to Yeong-Her Wang; yhw@ee.ncku.edu.tw

Received 6 February 2014; Revised 23 April 2014; Accepted 2 June 2014; Published 18 June 2014

Academic Editor: Nelson Tansu

Copyright (C) 2014 Pai-Yang Tsai et al. This is an open access article distributed under the Creative Commons Attribution License, which permits unrestricted use, distribution, and reproduction in any medium, provided the original work is properly cited.

\begin{abstract}
The temperature-dependent optical, electrical, and thermal properties of flip-chip light emitting diodes (FCLEDs) with diamondlike carbon (DLC) heat-spreading layers were investigated. On the basis of the measured results in the $20^{\circ} \mathrm{C}$ to $100^{\circ} \mathrm{C}$ temperature range, a significant performance improvement can be achieved for FCLEDs with DLC heat-spreading layers (DLC-FCLED) compared with FCLEDs without DLC heat-spreading layers (non-DLC-FCLED). The external quantum efficiency (EQE) of the DLC-FCLED improves by $9 \%$ at an injection current of $1000 \mathrm{~mA}$ and a temperature of $100^{\circ} \mathrm{C}$. The forward voltage and spectra variations are smaller than those of non-DLC-FCLEDs. The DLC-FCLED provides high efficiency and high stability performance for high-power and high-temperature applications.
\end{abstract}

\section{Introduction}

GaN-based light emitter diodes (LEDs) are widely used for automotive lighting, solid-state lighting, and as light engines for other illumination tools $[1,2]$. LEDs should operate at high injection currents and employ a large chip size when used for high-power applications. Therefore, the generated heat in LED chip and package is significant and cannot be neglected. The chip characteristics of conventional lateral LEDs are limited by technical problems; that is, the sapphire substrate suffers from poor electric and thermal properties [3]. For flip-chip LEDs (FCLED), both the $\mathrm{p}$ and $\mathrm{n}$ pads are attached to a high thermal conductivity substrate by eutectic bonding or solder bumps. However, the current crowding is still not improved because the current circuit of the $p$ and $\mathrm{n}$ pads is almost the same as conventional lateral LEDs [4]. Therefore, the generated heat in the hot spot of the current crowding area significantly degrades the electric and optical properties of a device. Diamond-like carbon (DLC) possesses high thermal conductivity, thermal diffusivity, and thermal radiation; furthermore, the coefficient of thermal expansion (CTE) of DLC is similar to that of GaN. DLC has very good thermal conductivity $(600 \mathrm{~W} / \mathrm{mK})$ and thermal diffusivity $\left(370 \mathrm{~mm}^{2} / \mathrm{s}\right)$, that is, 1.5 and 3.3 times higher than that of copper $[5,6]$. The DLC can be very effective for heat dissipation and hot spot removal. Therefore, the DLC improves chip performance at high injection current densities $[7,8]$.

In this study, the DLC was used as a heat-spreading layer between the mirror and eutectic material. For the fabricated DLC-FCLEDs, the temperature-dependent chip performance was discussed and compared with a FCLED without a DLC heat-spreading layer (non-DLC-FCLED).

\section{Experimental}

The schematic of the LED cross section is shown in Figure 1. The GaN LED epilayers were grown by metal-organic chemical vapor depositions onto (0001) sapphire substrates. The LED structure consisted of a low-temperature $200 \mathrm{~nm}$ thick GaN buffer layer, a $2 \mu \mathrm{m}$ thick undoped GaN layer, a $2 \mu \mathrm{m}$ thick and highly conductive n-type GaN layer, an InGaNGaN multiple-quantum-well (MQW) active layer, and a 


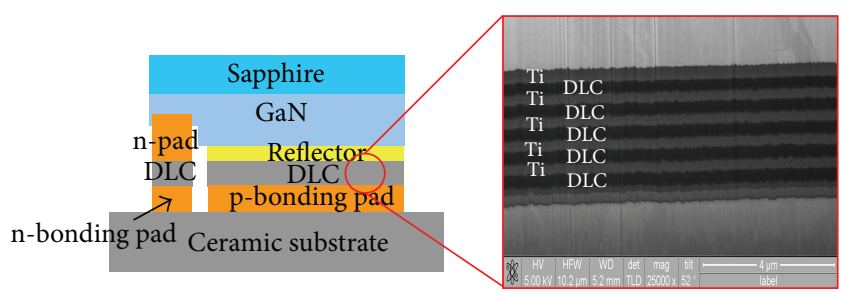

(a)

(b)

FIgURE 1: (a) Schematics of the FCLED with DLC heat-spreading layer. (b) Cross-sectional DLC heat-spreading layer SEM image for FCLED.

$0.5 \mu \mathrm{m}$ thick p-type GaN layer. A $1 \times 1 \mathrm{~mm}^{2}$ square isolation structure was created by using an inductively coupled plasma etcher (ICP) for electrical isolation. The $\mathrm{p}-\mathrm{GaN}$ was etched by an ICP to expose the $\mathrm{n}-\mathrm{GaN}$ for electrode deposition. $\mathrm{Cr} / \mathrm{Pt} / \mathrm{Au}$ were deposited on the $\mathrm{n}-\mathrm{GaN}$ as $\mathrm{n}$ pads, and the $\mathrm{Ni} / \mathrm{Ag} / \mathrm{Ti} / \mathrm{Au}$ metals were deposited on the $\mathrm{p}-\mathrm{GaN}$ film. These metals acted as the ohmic contact and reflective mirrors formed by electron beam (E-beam) evaporation. The $\mathrm{SiO}_{2}$ film was used to passivate the sidewall of the LED device through plasma-enhanced chemical vapor deposition. The Ti/DLC $(250 \mathrm{~nm} / 200 \mathrm{~nm})$ materials were used as heat-spreading layers by physical vapor deposition after passivation. The use of a Ti-layer can increase the adhesion and electrical conductivity of the DLC heat-spreading layer. Finally, Ti/Ni/AuSn was used as the bonding material layer for die attachment. To measure the temperature dependent on the FCLED characteristics, the FCLED was attached to a ceramic substrate by using AuSn eutectic bonding.

The LED chip was loaded onto a thermal plate composed of a copper stage, thermoelectric cooler, and thermistor. The temperature ranged from $20^{\circ} \mathrm{C}$ to $100^{\circ} \mathrm{C}$ for measuring purposes. The optical, spectral, and electric characteristics were measured by using an integrated sphere at various heat sink temperatures.

\section{Results and Discussion}

The performances of the split-wafer DLC-FCLED and the non-DLC-FCLED were investigated. The light output power, injection current, and forward voltage (L-I-V) characteristics at room temperature are shown in Figure 2. At $350 \mathrm{~mA}$, the forward voltage $\left(V_{F}\right)$ of the DLC-FCLED is $2.88 \mathrm{~V}$, whereas the forward voltage $\left(V_{F}\right)$ of the non-DLC-FCLED is $2.86 \mathrm{~V}$. The current-voltage curves are almost the same. The light output power is $414.2 \mathrm{~mW}$ for the DLC-FCLED and $401.3 \mathrm{~mW}$ for the non-DLC-FCLED. The corresponding wall-plug efficiencies (light output power/injection current $x$ forward voltage) of DLC-FCLED and non-DLC-FCLED at $350 \mathrm{~mA}$ are $41.1 \%$ and $40.1 \%$, respectively. No significant difference was observed in the device performance of the DLC-FCLED and non-DLC-FCLED. The heat generated in the epilayers is almost the same.

The light output power of the DLC-FCLED is higher than the non-DLC-FCLED at an injection current of 1,000 mA.

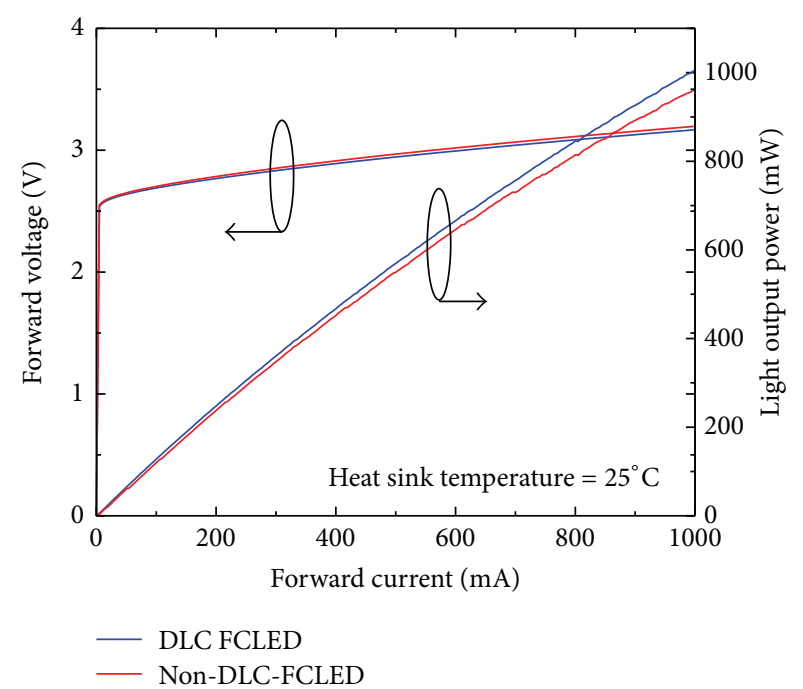

FIGURE 2: L-I-V characteristics of the DLC-VLED and non-DLCVLED.

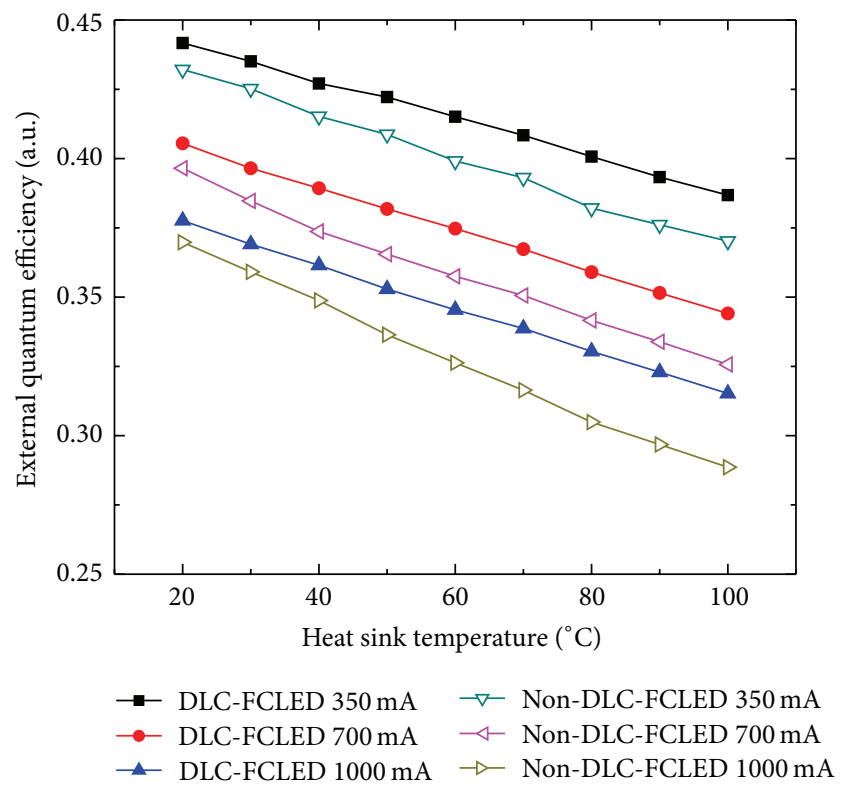

FIgure 3: Three EQEs of the DLC-FCLED and non-DLC-FCLED as functions of the heat sink temperature at different injection currents (350, 700, and 1,000 mA).

The DLC can provide better thermal conductivity and thermal radiation. Furthermore, the heat of the MQW can be uniformly spread on the DLC film and can be transferred to the ceramic substrate. The light output power can be further improved by using the DLC heat-spreading layers at high injection currents.

Figure 3 shows the external quantum efficiency (EQE, (light output power $/ h v) /($ injection current/e), where $h$ is the Planck constant, $v$ is frequency, and $e$ is the elementary charge) of the DLC-FCLED and non-DLC-FCLED as a function of the heat sink temperature at injection currents of 350,700 , and 1,000 mA. At an injection current of $350 \mathrm{~mA}$ 


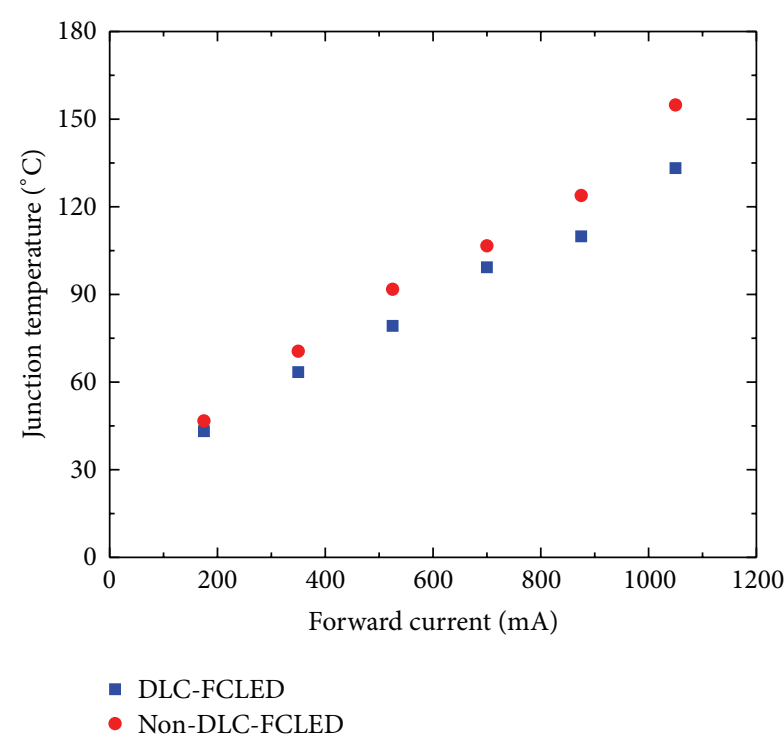

FIGURE 4: Junction temperature as a function of the injection current for the DLC-FCLED and the non-DLC-FCLED.

and with a heat sink temperature of $20^{\circ} \mathrm{C}$, the EQE of the DLC-FCLED and non-DLC-FCLED are $44.1 \%$ and $43.2 \%$, respectively. The EQE of the DLC-FCLED is slightly higher than the EQE of the non-DLC-FCLED. At a heat sink temperature of $100^{\circ} \mathrm{C}$, the EQE decreases to $38.6 \%$ and $37 \%$ for the DLC-FCLED and non-DLC-FCLED, respectively. The EQE of the DLC-FCLED improves by $5 \%$. The heat from the chip can be removed by the DLC heat-spreading layer and ceramic substrate. At an injection current of $1,000 \mathrm{~mA}$ and at a heat sink temperature of $20^{\circ} \mathrm{C}$, the EQE of the DLCFCLED and non-DLC-LED decreases by $37.7 \%$ and $36.9 \%$, respectively. All sample efficiencies decrease with increasing heat sink temperature. The droop rate of the EQE for the DLC-FCLED was lower than that of the non-DLC-FCLED. The EQE of the non-DLC-FCLED is $36.9 \%$ and decreased to $28.8 \%$ at $1,000 \mathrm{~mA}$, thus indicating a droop rate of $21.9 \%$. The droop rate of the DLC-FCLED EQE is $16.5 \%$. The effect of the DLC heat-spreading layer on the light extraction performance of the FCLED is significant at high injection currents within a particular heat sink temperature range.

The junction temperatures of the DLC-FCLED and nonDLC-FCLED are measured by the forward voltage method. Figure 4 shows the junction temperature as a function of the injection current for the DLC-FCLED and non-DLC-FCLED. For the non-DLC-LED, the junction temperatures are 70.5 and $154.8^{\circ} \mathrm{C}$ at 350 and $1,000 \mathrm{~mA}$, respectively. However, the DLC-FCLED exhibited lower junction temperatures with 63.4 and $133.2^{\circ} \mathrm{C}$ at 350 and $1,000 \mathrm{~mA}$, respectively. Thus, a lower junction temperature is achieved for the DLCFCLED. This result can be attributed to the better thermal conductivity, thermal diffusivity, and thermal radiation of the DLC. The high thermal diffusivity can effectively remove the generated heat and decrease temperature differences. Therefore, the heat generated at a junction is efficiently spread by the DLC layer on the ceramic substrate. According to the Stefan-Boltzmann equation, the power of black body

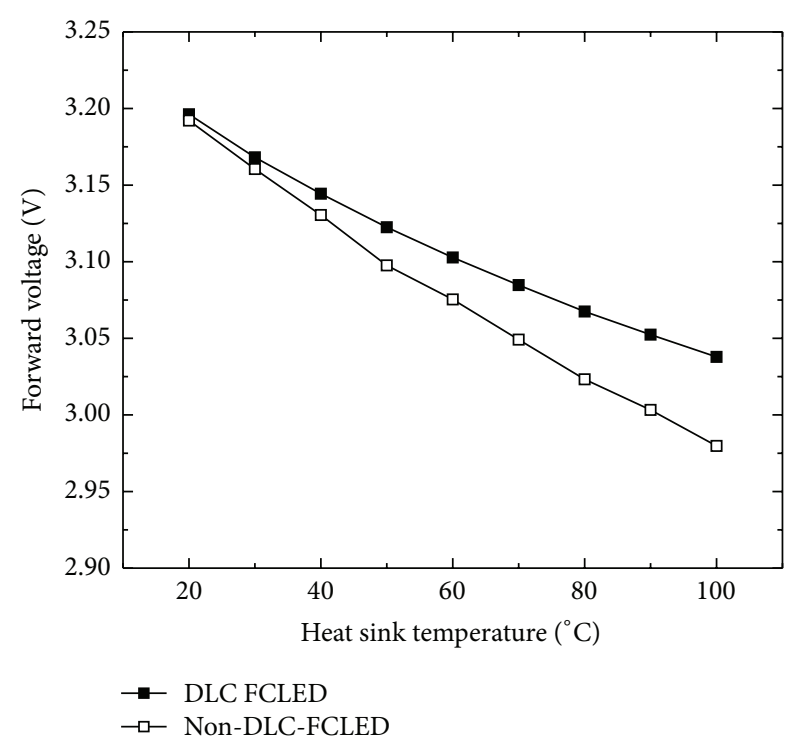

FIgURE 5: The forward voltage as a function of the heat sink temperature at an injection current of $1,000 \mathrm{~mA}$.

radiation may be calculated as $5.67 \times 10^{-8} \mathrm{~T}(\mathrm{~K})^{4} \mathrm{~W} / \mathrm{m}^{2}$, and the power radiated is about $0.15 \mathrm{~W} / \mathrm{cm}^{2}$. This value is about $5 \%$ of the input power of devices.

Figure 5 shows that the forward voltage changes according to the heat sink temperature. The forward voltage decreases with increasing heat sink temperature because of chip heating. At 1,000 mA, the forward voltage of the DLCFCLED decreases from $3.19 \mathrm{~V}$ to $3.03 \mathrm{~V}$ with increasing heat sink temperature from $20^{\circ} \mathrm{C}$ to $100^{\circ} \mathrm{C}$. By contrast, the voltage for the non-DLC-FCLED decreases from 3.19 V to $2.97 \mathrm{~V}$. The energy band gap narrows with decreasing forward voltage because of the internally generated heat of the chip. The forward voltage of the DLC-FCLED slightly decreases with increasing heat sink temperature from $20^{\circ} \mathrm{C}$ to $100^{\circ} \mathrm{C}$. This can be attributed to the better thermal dissipation of the DLC heat-spreading layer.

The FCLED with a DLC heat-spreading layer can decrease wavelength shifts with increasing heat sink temperature. The electroluminescence (EL) spectra of the DLC-FCLED and non-DLC-FCLED at various heat sink temperatures and at an injection current of 1,000 mA are shown in Figure 6. The EL intensities decrease with increasing heat sink temperature; this result may be caused by the heating of the chip. The increase in heat sink temperature decreases the energy band gap. The EL spectra are represented by a red shift (Figures 6(a) and 6(b)). The wavelength peak of the DLC-FCLED is $448.4 \mathrm{~nm}$ at $20^{\circ} \mathrm{C}$, and the EL spectra shifted to $451.9 \mathrm{~nm}$ at $100^{\circ} \mathrm{C}$. The wavelength shifted by $3.5 \mathrm{~nm}$ at heat sink temperatures of $20^{\circ} \mathrm{C}$ to $100^{\circ} \mathrm{C}$. The wavelength peak of nonDLC-FCLED is $448.2 \mathrm{~nm}$ at $20^{\circ} \mathrm{C}$ and its EL spectra shifts to $452.1 \mathrm{~nm}$ at $100^{\circ} \mathrm{C}$. The wavelength shifted by $3.9 \mathrm{~nm}$ in heat sink temperatures between $20^{\circ} \mathrm{C}$ and $100^{\circ} \mathrm{C}$.

To validate the effect of DLC heat-spreading layers, each 10 random selected chips for DLC-FCLED and nonDLC-FCLED were adopted for the junction temperature measurement. As results show in Figure 7 at an injection 


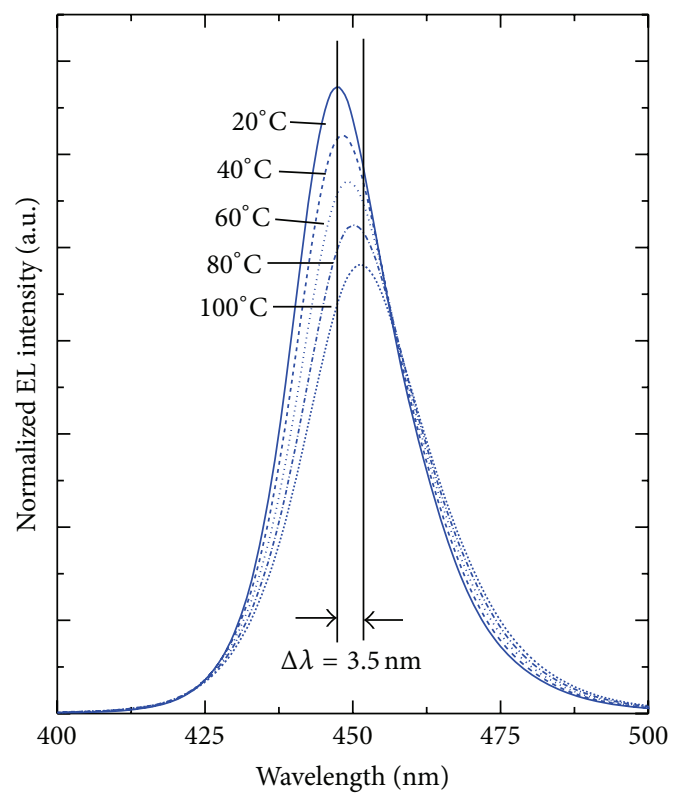

(a)

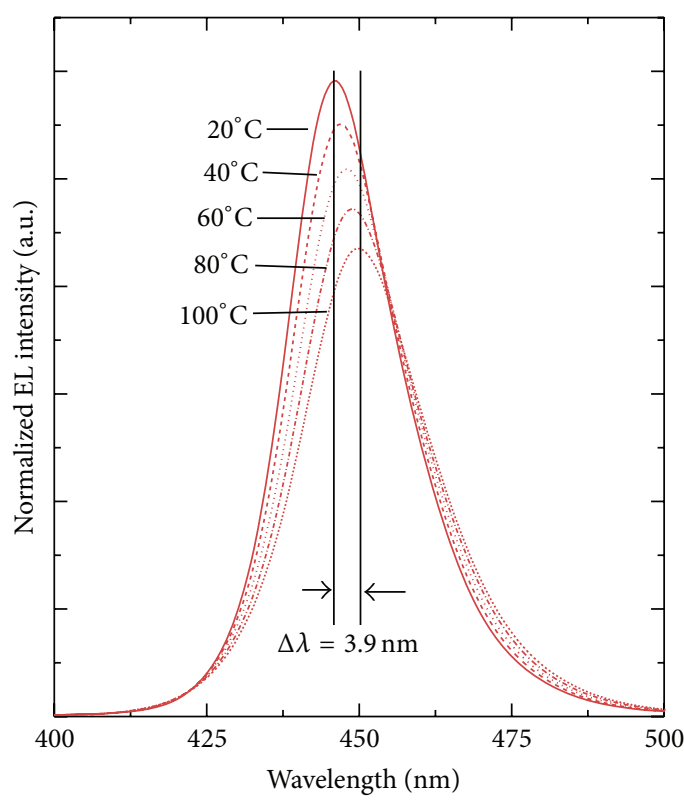

(b)

Figure 6: Normalized EL spectra as a function of the heat sink temperature for the (a) DLC-FCLED and (b) non-DLC-FCLED with an injection current of $1000 \mathrm{~mA}$.

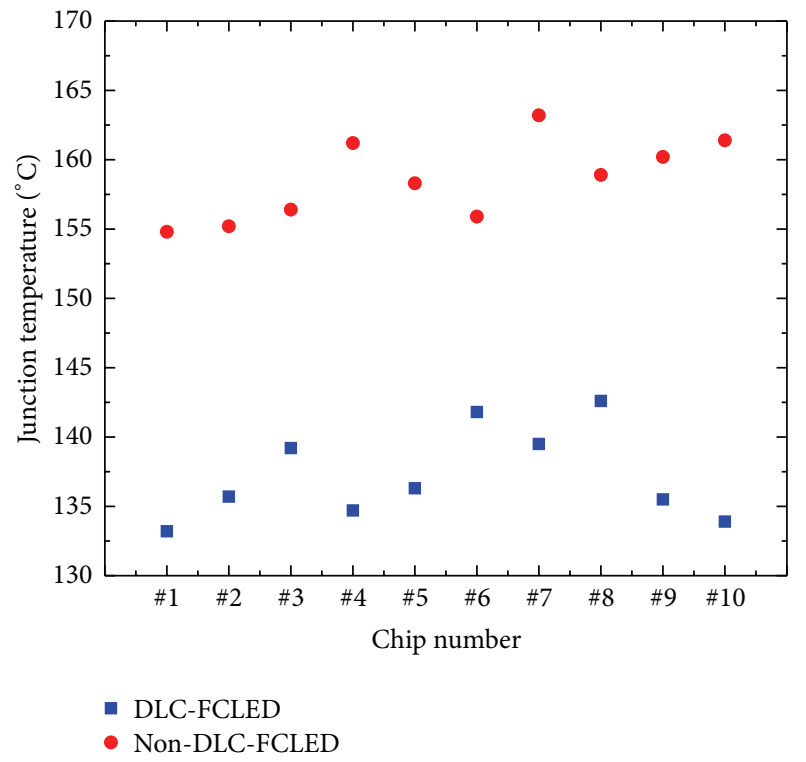

FIGURE 7: Junction temperature measurements for 10 DLC-FCLED and 10 non-DLC-FCLED chips at an injection current of $1000 \mathrm{~mA}$. The chips were randomly selected.

current of $1000 \mathrm{~mA}$, the FCLED with DLC heat-spreading layer shows the lower junction temperature as compared to that of non-DLC-FCLED. The trend is very consistent which indicates the role of the DLC heat-spreading layers is very effective in heating dissipation and hot spot removal. The performance difference is unlikely to be related to the process variation.

\section{Conclusions}

This paper demonstrates that the use of DLC heat-spreading layers can improve the optical and thermal properties of FCLEDs. The temperature-dependent device performance of the DLC-FCLED is significantly improved compared with the performance of the non-DLC-FCLED. At an injection current of $1,000 \mathrm{~mA}$, the light output power and $\mathrm{EQE}$ are $952.1 \mathrm{~mW}$ and $28.8 \%$ for the non-DLC-FCLED. By contrast, the light output power and EQE increase to $1,006.3 \mathrm{~mW}$ and $31.5 \%$, respectively, for the DLC-FCLED. The forward voltage and EL spectra variations are smaller for the DLC-FCLED. At heat sink temperatures between $20^{\circ} \mathrm{C}$ and $100^{\circ} \mathrm{C}$, the forward voltage decreases by $0.17 \mathrm{~V}$, which is less than the voltage for the non-DLC-FCLED at an injection current of 1,000 mA. The EL spectra of the DLC-FCLED show the red shift of only $3.5 \mathrm{~nm}$. This shift is less than the shift of the nonDLC-FCLED at $0.4 \mathrm{~nm}$. These results demonstrate the stable optical, electrical, and thermal properties of FCLEDs in highpower or high-temperature applications.

\section{Conflict of Interests}

The authors declare that there is no conflict of interests regarding the publication of this paper.

\section{References}

[1] D. F. Feezell, J. S. Speck, S. P. Denbaars, and S. Nakamura, "Semipolar (2021) InGaN/GaN light-emitting diodes for highefficiency solid-state lighting," IEEE/OSA Journal of Display Technology, vol. 9, no. 4, pp. 190-198, 2013. 
[2] C.-T. Lee, U.-Z. Yang, C.-S. Lee, and P.-S. Chen, "White light emission of monolithic carbon-implanted InGaN-GaN lightemitting diodes," IEEE Photonics Technology Letters, vol. 18, no. 19, pp. 2029-2031, 2006.

[3] T. Egawa, B. Zhang, and H. Ishikawa, "High performance of InGaN LEDs on (111) silicon substrates grown by MOCVD," IEEE Electron Device Letters, vol. 26, no. 3, pp. 169-171, 2005.

[4] O. B. Shchekin, J. E. Epler, T. A. Trottier et al., "High performance thin-film flip-chip InGaN-GaN light-emitting diodes," Applied Physics Letters, vol. 89, no. 7, Article ID 071109, 2006.

[5] K. M. Leung, A. C. Cheung, B. C. Liu et al., "Measuring thermal conductivity of CVD diamond and diamond-like films on silicon substrates by holographic interferometry," Diamond and Related Materials, vol. 8, no. 8-9, pp. 1607-1610, 1999.

[6] C. M. Sung and M. C. Kan, "Cold cathode fluorescence light with amorphous diamond coated electrodes," Nano Science and Technology Institute-Nanotech, vol. 1, pp. 239-243, 2006.

[7] P. Y. Tsai, H. K. Huang, C.-M. Sung, M. C. Kan, and Y. H. Wang, "InGaN/GaN vertical light-emitting diodes with diamondlike carbon/titanium heat-spreading layers," IEEE Electron Device Letters, vol. 34, no. 8, pp. 1029-1031, 2013.

[8] R. H. Horng, K. C. Shen, C. H. Tien, S. C. Lin, and D. S. Wuu, "Performance of Cu-plating vertical LEDs in heat dissipation using diamond-like carbon," IEEE Electron Device Letters, vol. 35, no. 2, pp. 169-171, 2014. 

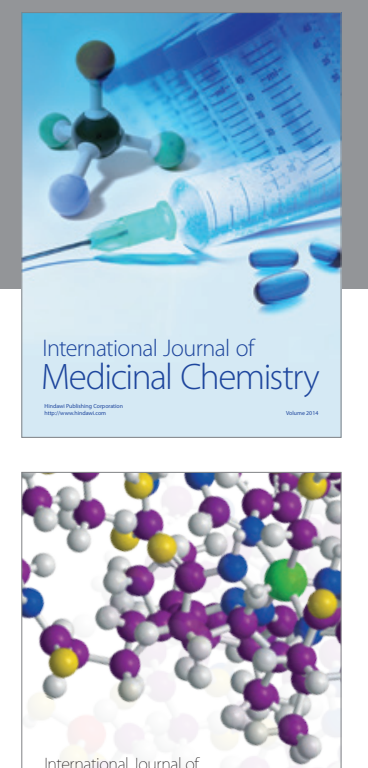

\section{Carbohydrate} Chemistry

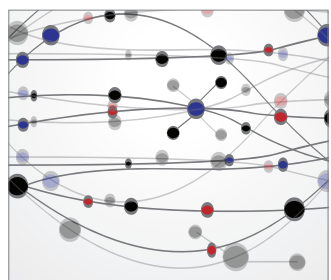

The Scientific World Journal
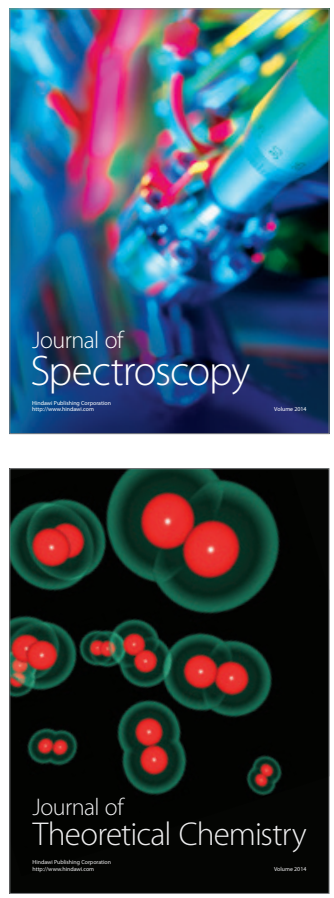
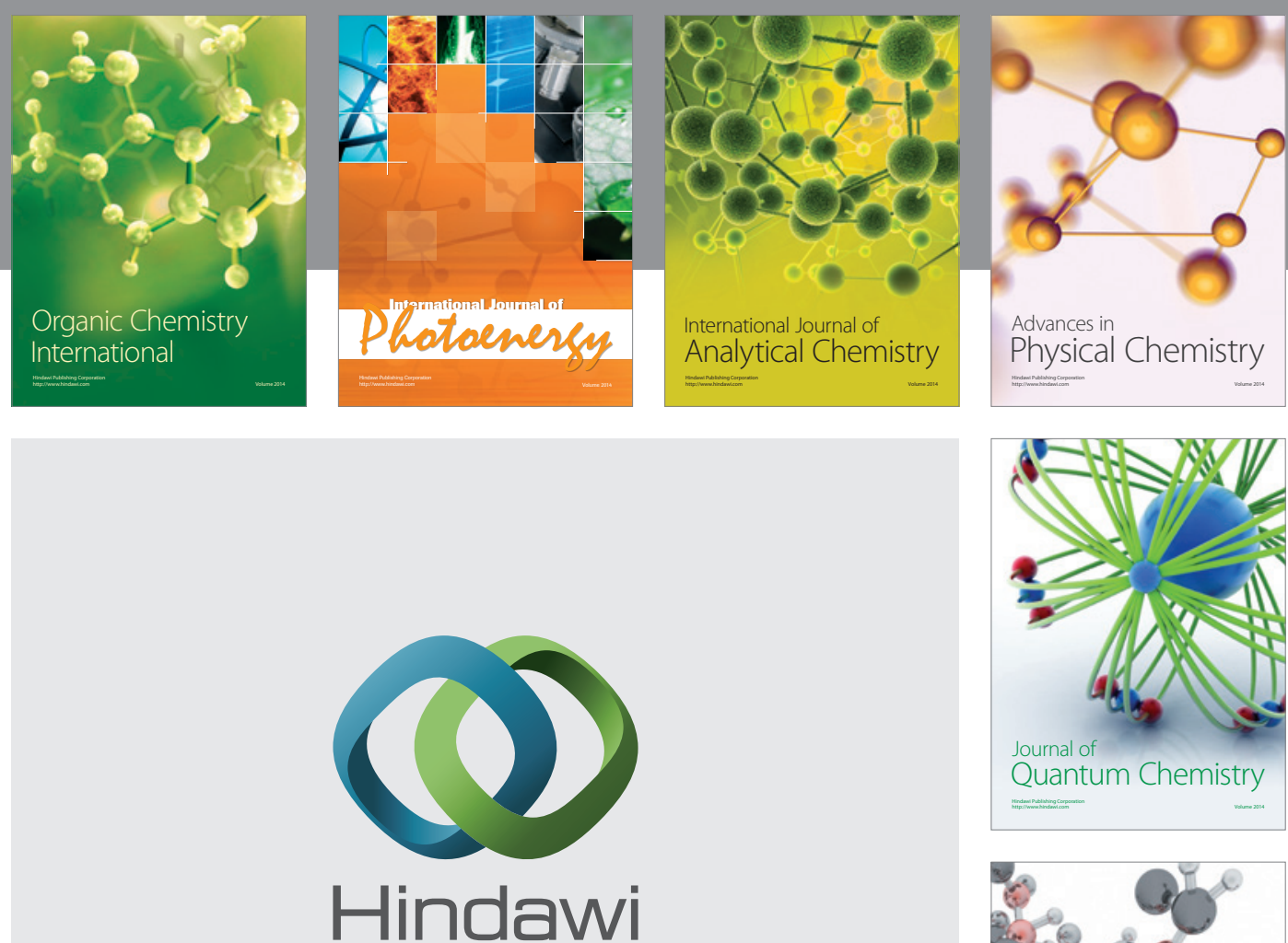

Submit your manuscripts at

http://www.hindawi.com

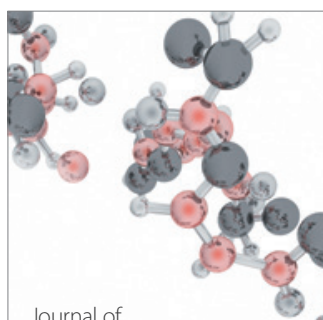

Analytical Methods

in Chemistry

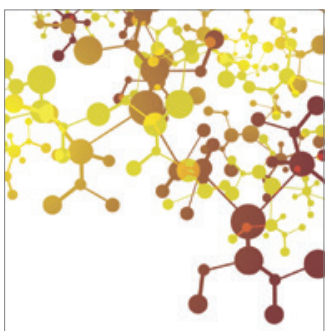

Journal of

Applied Chemistry

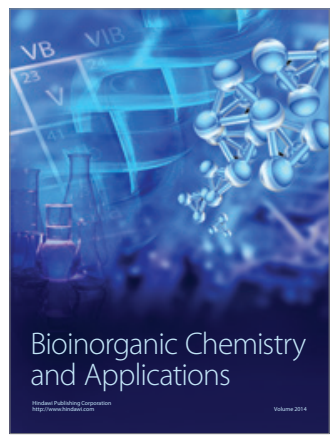

Inorganic Chemistry
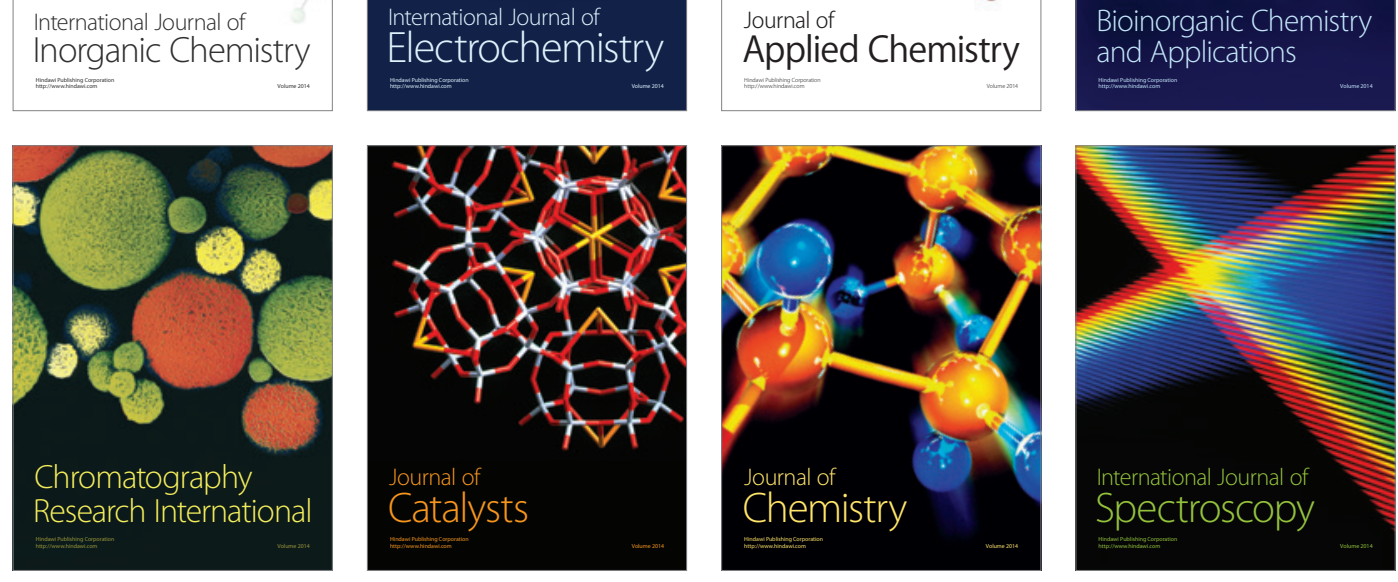